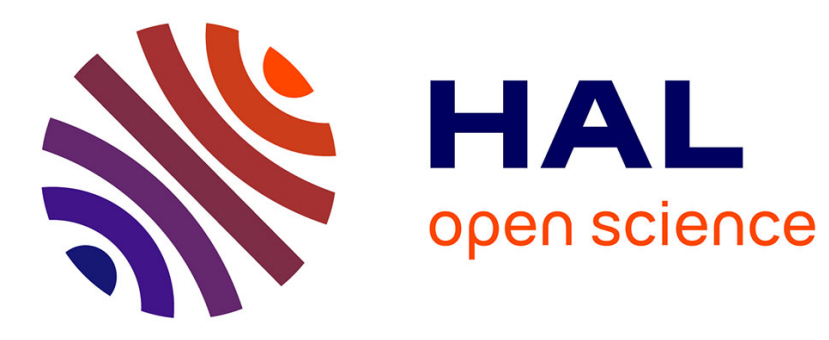

\title{
Novel PDMS based semi-interpenetrating networks (IPNs) for the extraction of phenolic compounds
}

Imen Abdelhadi-Miladi, Taha Chabbah, Saber Chatti, Houyem Abderrazak, Patrice Saint-Martin, Hervé Casabianca, Catherine Marestin, Régis Mercier, Hatem Ben Romdhane, Emmanuelle Vulliet, et al.

\section{To cite this version:}

Imen Abdelhadi-Miladi, Taha Chabbah, Saber Chatti, Houyem Abderrazak, Patrice Saint-Martin, et al.. Novel PDMS based semi-interpenetrating networks (IPNs) for the extraction of phenolic compounds. Journal of Environmental Chemical Engineering, 2021, 9 (1), pp.104656. 10.1016/j.jece.2020.104656 . hal-03119656

\section{HAL Id: hal-03119656 \\ https://hal.science/hal-03119656}

Submitted on 29 Sep 2021

HAL is a multi-disciplinary open access archive for the deposit and dissemination of scientific research documents, whether they are published or not. The documents may come from teaching and research institutions in France or abroad, or from public or private research centers.
L'archive ouverte pluridisciplinaire HAL, est destinée au dépôt et à la diffusion de documents scientifiques de niveau recherche, publiés ou non, émanant des établissements d'enseignement et de recherche français ou étrangers, des laboratoires publics ou privés. 


\title{
Novel PDMS based Semi-Interpenetrating Networks (IPNs) for the extraction of phenolic compounds
}

Imen Abdelhadi-Miladi ${ }^{1}$, Taha Chabbah ${ }^{2,5}$, Saber Chatti $^{2}$, Houyem Abderrazak ${ }^{2}$, Patrice Saint-Martin ${ }^{3}$, Hervé Casabianca $^{3}$, Catherine Marestin ${ }^{4}$, Régis Mercier ${ }^{4}$, Hatem Ben Romdhane ${ }^{1}$, Emmanuelle Vulliet ${ }^{3}$, Abdelhamid Errachid $^{3}$ and Nicole Jaffrezic-Renault ${ }^{3, *}$

${ }^{1}$ University of Tunis El Manar, Faculty of Sciences of Tunis, Laboratory of Chemistry (Bio), Organic, Structural and Polymer - Synthesis and Physicochemical Study (LR99ES14), 2092 El Manar, Tunisia.

2 National Institute of Research and Physicochemical Analysis (INRAP), Biotechnopole of Sidi Thabet, 2020 Ariana, Tunisia

${ }^{3}$ University of Lyon, Institute of Analytical Sciences, UMR 5280, 5 Rue de la Doua, 69100 Villeurbanne, France

${ }^{4}$ University of Lyon, Institute of Polymer Materials, UMR 5223, 5 Rue V. Grignard, 69622 Villeurbanne Cedex, France

${ }^{5}$ University of Tunis El Manar, Faculty of Sciences, Farhat Hached Universitary campus, 1068 Tunis, Tunisia

* Corresponding Author: nicole.jaffrezic@univ-lyon1.fr

\begin{abstract}
:
Four Semi-Interpenetrating Networks (semi-IPN) based on polydimethylsiloxane (PDMS) were developed for the sorptive extraction of polar phenolic compounds ( $\log$ Kow $\leq 3)$. Their preparation is based on the hydrosilylation crosslinking reaction of dihydrosilane terminated polydimethylsiloxane with its homologue divinyl, followed by the addition of inert various polyethylene oxide derivatives (PEO). The physico-chemical properties of the semi-IPN were controlled by Differential Scanning Calorimetry (DSC), Scanning Electronic Microscopy (SEM), RAMAN spectroscopy and contact angle measurements, showing the homogeneity of the semi-IPN and their higher hydrophilicity. Under optimum extraction conditions of phenolic molecules as target analytes and using liquid chromatography as analysis techniques, the novel modified PDMS phases showed good extraction rate against polar analytes with an excellent relative recovery average (69-100\%) for phenolic molecules. The higher retention rates were obtained with 30\% interpenetrated copolymer PEO/PPO in PDMS. Moreover, five adsorption/desorption cycles led to a loss of $5.8 \%$ of the adsorption efficiency, showing a good stability of these PDMS-based IPN phases.
\end{abstract}


Keywords: PDMS phase, PEO derivatives, semi-IPNs, extraction, reusability, phenolic molecules.

\section{Introduction}

Organic pollutants which are originally derived from domestic, industrial and agricultural activities are increasingly released into the wastewater leading consequently to the contamination of the soil and the environment. Among the common contaminants which are strongly dispersed in aquatic environment, we can note phenolic compounds or pesticides namely known for their intolerable toxicity [1-3]. On the other hand, the continuous population growth and therefore the anthropogenic activity increase will result in much more important chemical and organic substances release into the environment which can critically threaten the fauna and flora and most specifically humans. For this purpose, the research community is more and more focused to develop robust, low cost and environmentally friendly processes capable of removing pollutants from water and at the same time to safeguard the health of affected populations.

Among various extraction technologies the extraction process based on solid adsorbents have been widely adopted [4] and is the most popular treatment up to date since it is known as an environmental friendly method compared to solvent-based extraction and also because of convenience, ease of operation and simplicity of design. Such process is based on specific solid phases since the removal performance of analytes relies on the affinity of both adsorbent phase and the own character of each contaminant. Phenolic compounds were extracted using different types of materials, especially for analytical purposes (coupled with ultra-high performance liquid chromatography (HPLC) or gas chromatography (GC) with different types of detectors). Solvent impregnated agorose gel was used for microextraction of phenols [5] and polyacrylate coated silica fibers were used for the extraction of chlorinated phenols and nitrophenols [6]. PDMS (polydimethylsiloxane) materials is the king of the adsorbent phases for solid-phase micro-extraction (SPME) and stir bar sorptive extraction (SBSE) formats $[7,8]$. The main choice of PDMS phase is intimately related to its exceptional properties: a high hydrophobicity, a high flexibility allowing a high deformation ability to easily adopt various shapes, an UV and thermal stability, a low toxicity, a versatile cross-linking chemistry and a high gas permeability [9-11]. The hydrophobicity of PDMS enables high extraction rate 
of hydrophobic compounds. However, since the extraction of polar molecules is more difficult due to the strong interactions of these compounds with water molecules in aqueous solutions, therefore, the co-extraction of polar and non polar phenols by PDMS phases is challenging. Different chemical groups were introduced in the PDMS network to overcome the limitations of PDMS for the polar compounds: $\beta$-cyclodextrin [12], divinylbenzene [13], polyvinylalcohol [14]. In the present work, novel PDMS materials based on the insertion of various PEO (polyethylene oxide) derivatives were designed as novel solid adsorbents with better affinity for phenolic molecules. PMDS semi-IPN (inter-penetrating) phases were elaborated from two commercial PDMS chain precursors followed by the addition of various PEO (polyethylene oxide) derivatives as polymer modifiers (PM). After their physicochemical characterization, the extraction efficiency of the novel PDMS compounds, grounded as a powder form (diameter $<1 \mathrm{~mm}$ ) were determined for a series of phenolic target with different polarities $(\log$ Kow $\leq 3)$. Their recyclability was also tested.

\section{Experimental part:}

\section{1 - Research Methodology}

A flowchart of the research methodology is presented in Figure 1.

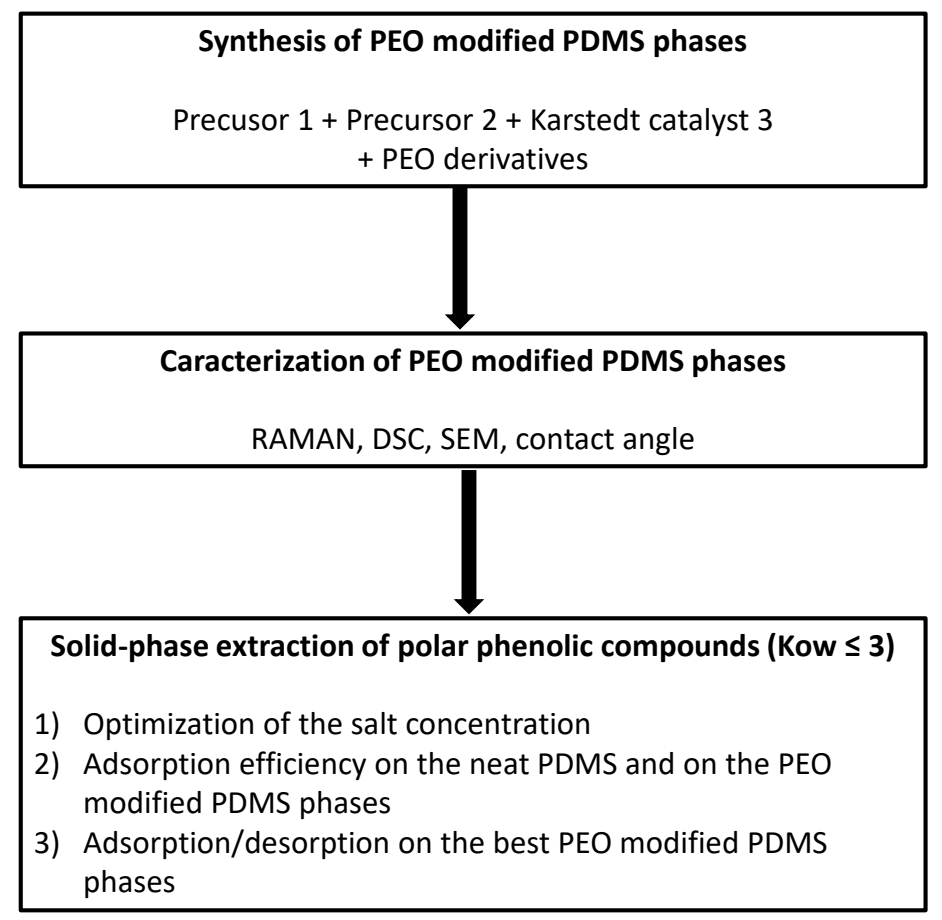

Figure 1. Flowchart of the research methodology 


\section{2- Reagents \& Materials:}

- Two kinds of PDMS precursors chains (RTV3428A \& RT3428VB) were used in this study and supplied, from Elkem Silicones, in oil form. The composition and the chemical structural characterization of each precursor have been, previously, accomplished using several techniques (NMR, Maldi TOF, DSC and SEC) [15]. As shown below, the first transparent oil material RTVA (Precursor 1) is the dihydrosilane-terminated PDMS (average molecular weigts or $\mathrm{M}_{\mathrm{n}}=16.700 \mathrm{~g} / \mathrm{mol}$, Polydispersity or $\mathrm{PD}=2.01$ ) and the second one with red rust color $\left(\mathrm{M}_{\mathrm{n}}=18200 \mathrm{~g} / \mathrm{mol}, \mathrm{PD}=3.27\right)$ is an oil composed from a combination between divinyl-terminated PDMS (Precursor 2) and Karsted catalyst 3 (0.5-1ppm) which is necessary for the crosslinking process.<smiles>C[SiH](C)O[Si](C)(C)O[Si](C)(C)C</smiles>

Precursor 1<smiles>C=C[Si](C)(C)O[Si](C)(C)O[Si](C)(C)C=C</smiles>

Precursor 2

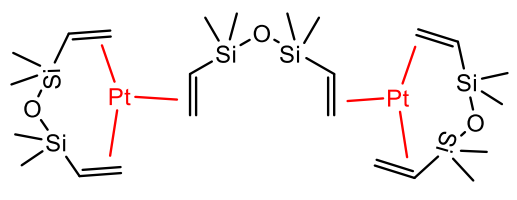

Karsted catalyst 3

- Four types of poly(ethylene oxide) (4-7) (PEO derivatives) were supplied from Sigma Aldrich as polymer modifiers.<smiles>CCCCCOC(C)C</smiles>

PEO (400 g.mol-1)

4

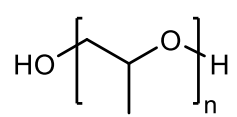

PPO (400 g.mol $\left.{ }^{-1}\right)$

5<smiles>CCCC(=O)OC(C)(C)COC</smiles>

PEO Laurate (400 g.mol-1)

6

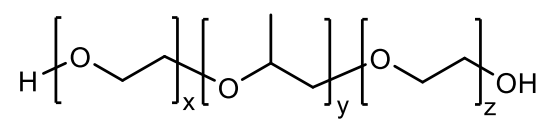

Breaker 2 (1750 g.mol $\left.{ }^{-1}\right)$

7

- p-hydroxy benzoic acid ( $\geq 99 \%$ ), caffeic acid ( $\geq 95 \%$ ), ferrulic acid ( $\geq 98 \%$ ), benzoic acid ( $\geq 99.5 \%$ ), anisic acid ( $\geq 98 \%$ ), toluic acid ( $\geq 98 \%$ ), p-chlorobenzoic acid (99\%), eugenol (99\%), t-anethol (99\%) were used as target analytes (phenols's class) and were purchased from Sigma Aldrich, France. Phosphoric acid ( $\geq 85 \%)$, HPLC grade acetonitrile and methanol were also purchased from Sigma Aldrich, France. Sodium Chloride (99.9\%) was purchased from Fischer Scientific (France).

\section{Characterization methods}

Raman Rxn1 spectrometer (Kaiser Optical Systems, Ann Arbor, USA), equipped with a thermoelectrically cooled CCD detector, was used in combination with a fiber optic sapphire immersion probe. The laser wavelength was $785 \mathrm{~nm}$. All spectra were recorded at a resolution 
of $4 \mathrm{~cm} 1$ in the spectral window from 150 to $3480 \mathrm{~cm} 1$. Data collection was controlled using the HoloGRAMS ${ }^{\text {TM }}$ software. Acquisition time was $5 \mathrm{~s}$ and five spectra were cumulated. For each sample analyzed, spectra acquisition was reiterated 3 times.

Differential Scanning Calorimetry (DSC) thermograms were obtained by using a METTLER TOLEDEO DSC882e Differential Scanning Calorimetry. The scanning temperature was performed from $-140{ }^{\circ} \mathrm{C}$ to $50^{\circ} \mathrm{C}$ using a heating rate of $10{ }^{\circ} \mathrm{C} / \mathrm{min}$ under nitrogen atmosphere.

Scanning electron microscopy (SEM) images were realized by using a VEGA TESCAN SEM.

Water contact angle (WCA) measurements were carried out using a Dataphysics Digidrop contact angle meter equipped with a CDD2/3 camera with the sessile drop method and by using Milli-Q quality water as probe liquid. The tabulated results are the average of at least five measurements on different parts of each sample.

\section{3- Preparation of solid phases based on PDMS material}

\section{3-1- Neat PDMS phase 8 (conventional PDMS phase)}

Neat networks were prepared based on the formulation provided by Elkem silicones with a ratio of (10:1) of dihydrosilane terminated PDMS 1 as bifunctional linear network chain and divinyl-terminated PDMS 2 as a crosslinker. The hydrosilylation reaction was catalyzed by a platinum complex (Karstedt catalyst) $\mathbf{3}$ which is already diluted on divinyl-PDMS $\mathbf{2}$ as received. These precursors were thoroughly mechanically mixed for $10 \mathrm{~min}$ at $110^{\circ} \mathrm{C}$ until caking and then the mixture was kept for curing for $24 \mathrm{~h}$ at $110^{\circ} \mathrm{C}$. The resultant neat PDMS $\mathbf{8}$ was obtained as a rigid elastic material with color of red rust.

\section{3-2- Novel modified PDMS phases 9-12}

The novel modified PDMS phases 9-12 were prepared through a reaction mixture of $\mathbf{1}$ and $\mathbf{2}$ with a ratio of $(10: 1)$, as for phase 8 , by the addition of different percentages $(10,20$ and $30 \%$ ) of polymers modifiers 4-7 (Table 1). To ensure the total interpenetration of these polymers modifiers through the crosslined chains, the synthesis was carried out as follows: the PEO derivative was firstly diluted in the dihydrosilane terminated PDMS $\mathbf{1}$ and homogenously mixed together at $110^{\circ} \mathrm{C}$ for nearly $10 \mathrm{~min}$. After cooling at room temperature, the second crosslinker 2 was added to the precursors and the mixture was manually mixed at $110^{\circ} \mathrm{C}$ until caking. The resulting materials named as semi-interpenetrating polymer networks 
(semi-IPNs) were allowed to cure at $110^{\circ} \mathrm{C}$ for $24 \mathrm{~h}$. All of them provided rigid elastic networks 9-12 with red rust colors.

Table 1: Composition of the neat PDMS and the modified PDMS phases

\begin{tabular}{|l|c|c|c|c|}
\hline Neat PDMS & \multicolumn{4}{|c|}{$1+2+3$} \\
\cline { 2 - 5 } PM & 4 & 5 & 6 & 7 \\
\hline Modified PDMS & 9 & 10 & 11 & 12 \\
\hline
\end{tabular}

\section{3-3- Homogeneity and miscibility study}

Before testing the prepared semi IPN phases as adsorbents, it is crucial to verify the complete polymerization of the PDMS, regardless the nature of the PM; this point was verified by RAMAN spectroscopy and by GPC. The miscibility of the resulting networks was verified by DSC and by SEM. In fact, The immiscibility between Polymer Modifier (PM) and the PDMS can lead to PM aggregates which is obviously not the required result. In fact, it was reported that Differential Scanning Calorimetry (DSC) is the most frequently and widely used technique to investigate the miscibility of polymer modifier inside the semi-IPN [16-18]. A widely accepted criterion of miscibility in a polymer blend is the disappearance of the glass transition temperature of the two peaks corresponding to both phases (i.e the polymer modifier and the original PDMS) present in the blends.

\section{4- Shaping of PDMS phases (8-12)}

The neat PDMS 8 as well as the semi-IPNs PDMS 9-12 were ground to the required size $(<1$ $\mathrm{mm}$, selected through a stainless steel sieve with diameter of $1.00 \mathrm{~mm}$ ) using a Cryogenic Grinders, in order to maximize the contact surface with pollutants on further analysis and extraction experiments (Figure 2(b)).

\section{5- Preparation of the aqueous solutions of the phenolic compounds:}

The aqueous solutions containing the phenolic molecules were prepared in distilled water at concentration $1 \mathrm{ppm}(1 \mathrm{mg} / \mathrm{L})$. Doped solution containing the target polyphenols: After weighing the exact mass of each solid phenolic compound in aluminum capsules, it was successively introduced into a vial of $1 \mathrm{~L}$ and then filled with distilled water. The $\mathrm{pH}$ of the aqueous solution was adjusted to 2 by the addition of $2 \mathrm{~mL}$ of phosphoric acid. The mixture was kept under agitation for $24 \mathrm{~h}$ in order to ensure a total dissolution of all solid phenols. 


\section{6- Extraction procedure}

In order to test the extraction efficiency of each developed PDMS phase, we firstly started by studying the optimum conditions for a maximum recovery of the target molecules. For this purpose, several doped aqueous solutions (phenols) with the addition of salt (as matrix modifier) and the elaborated PDMS phases (with various percentages of PM) were prepared.

- Preparation of samples used for the salting-out effect study:

The corresponding solutions were prepared as follows: in a vial of $20 \mathrm{~mL}, 60 \mathrm{mg}$ of neat PDMS phase 8 was introduced with the addition of $10 \mathrm{~mL}$ of solutions containing the target phenolic compounds and different percentages of sodium chloride: $0 \%, 10 \%$ and $30 \%$, respectively. All solutions were deposited on a magnetic multistirrer and kept under constant agitation $(900 \mathrm{rpm})$ for different durations: 1 hour, 5 hours and 24 hours. After each time interval, a sample volume of $0.5 \mathrm{~mL}$ was taken from each solution and filtered with a $0.45 \mu \mathrm{m}$ PTFE filter and subsequently analyzed by HPLC /DAD technique (wavelength: $210 \mathrm{~nm}$ ). The HPLC system and the analytical conditions were described in more detail in previous work [19]. The adsorption efficiency is calculated according to Equation 1.

$$
\text { Adsorption efficiency }=\left(\frac{\mathrm{Ci}-\mathrm{Ct}}{\mathrm{Ci}}\right) * 100
$$

Where Ci: initial concentration $\left(\mathrm{mmol} \mathrm{l}^{-1}\right), \mathrm{Ct}$ : the residual concentration of the pollutant at time $\mathrm{t}$.

\section{Results and discussion}

\section{1- Preparation of novel solid adsorbent phases based on PDMS}

In this work, it is intended both: to prepare a PDMS network 8 (Neat PDMS) to be used as adsorbent phase for extraction process and to incorporate polymer modifiers (PEO derivatives 4-7) into the PDMS network to obtain novel PDMS solid adsorbents phases. The neat PDMS as well as the novel elaborated phases will be tested as adsorbents and the added value of the PM will be studied.

The most important reason for the use of PEO derivatives 4-7 as polymer modifiers is due to their polarity which can ensure a higher affinity to polar analytes. However, the mass of the modifying polymer is a crucial parameter involved in the extraction efficiency of the 
adsorbent phase. Therefore, an optimization study was carried out based on an optimum of extraction of several modified PDMS phases elaborated using different percentages $(10 \%, 20$ $\%$ and $30 \%$ ) of each PEO derivatives.

The incorporation of these linear PM into the PDMS network have been performed in-situ, as it was detailed in the experimental part, leading to a new class of PDMS semi-Interpenetrating Networks. The obtained materials 9-12 can be described as a polymeric network consisting on cross-linked chains having nodes originated from the hydrosilylation reaction [20-22] of the vinyl end with the hydrosilane end of the corresponding PDMS precursor (1) between which linear chains of PEO derivatives 4-7 are interpenetrated as schematically illustrated in Figure 2(a). [23-25]. The desappearance of the Si-H bond was monitored by RAMAN spectroscopy. The corresponding band at $2120 \mathrm{~cm}^{-1}$ ( $\mathrm{Si}-\mathrm{H}$ terminal) decreases during $120 \mathrm{~min}$ at $20^{\circ} \mathrm{C}$ and then stabilizes (Figure 3), regardless the percentage of PM. The reaction time decreases when the temperature is higher.

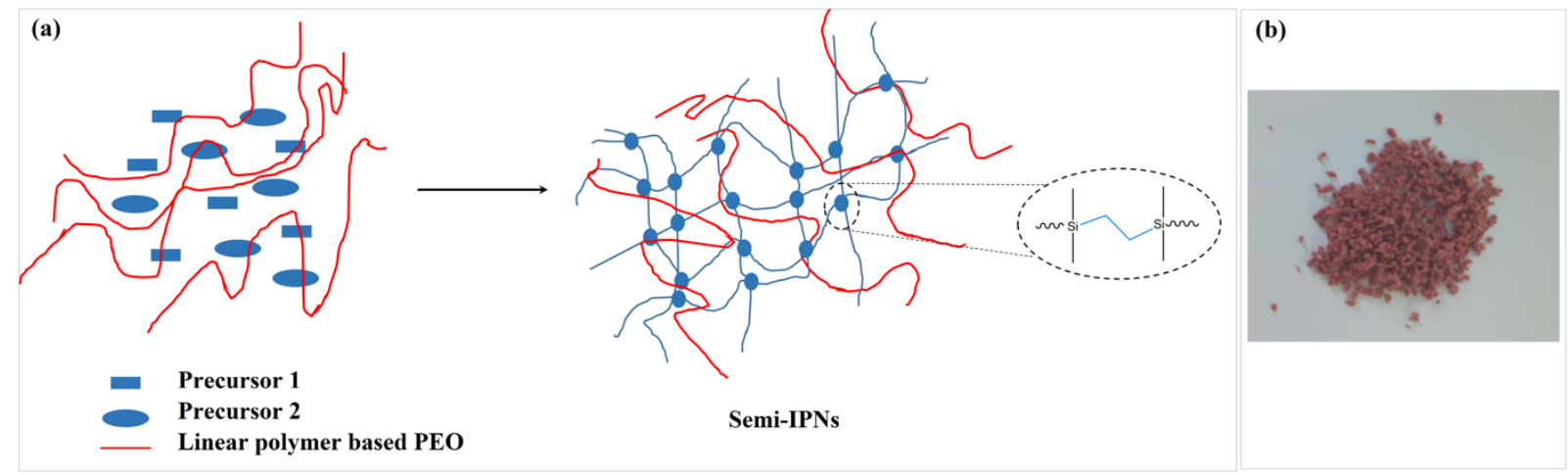

Figure 2. (a) Schematic presentation of PDMS Semi-IPNs (b) The resulting powder after (diameter $<1 \mathrm{~mm}$ ) 


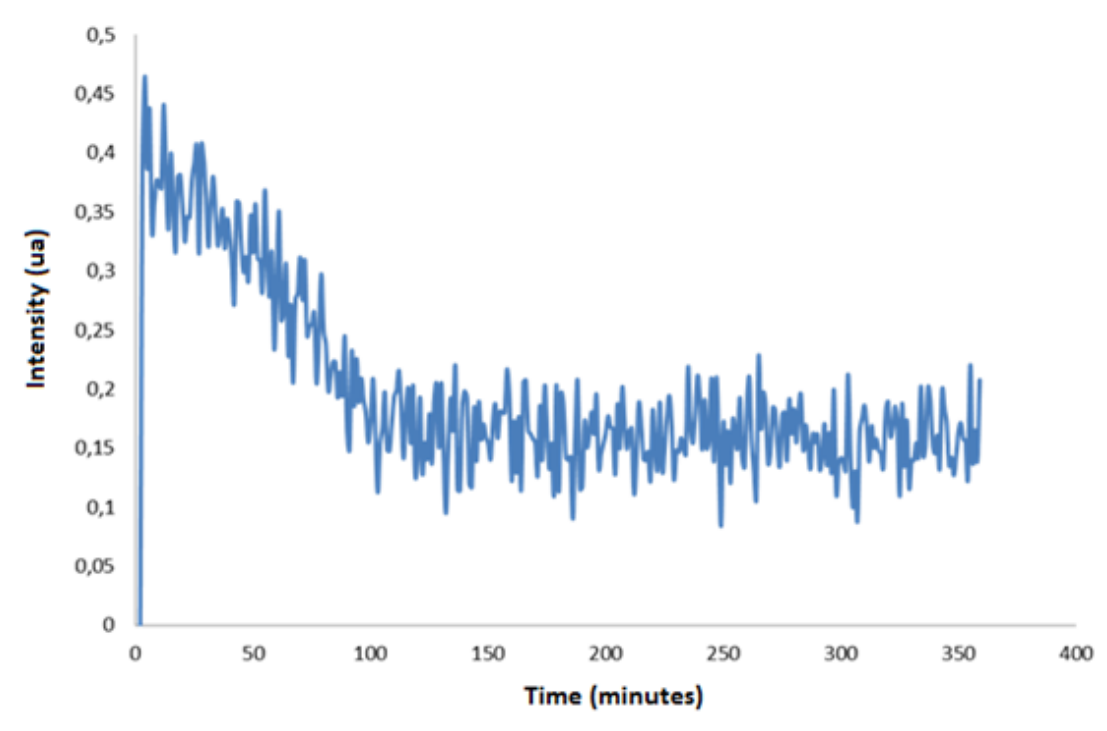

Figure 3. Monitoring of the terminal $\mathrm{Si}-\mathrm{H}$ bond by Raman spectrocopy.

DSC was used to control the miscibility of polymer modifier inside the semi-IPN. The glass transition temperatures obtained for the PEO-derivatives (4-7), neat PDMS (8) and semi-IPNs (9-12) are presented in Table 2.

Table 2. Glass transition temperatures (Tg) of Neat PDMS (8), semi-IPNs phases and their corresponding polymer modifiers

\begin{tabular}{|c|c|}
\hline PM and Semi-IPNs phases & $\operatorname{Tg}\left({ }^{\circ} \mathrm{C}\right)$ \\
\hline A) PDMS (8) & -117 \\
\hline PM (4) & -63 \\
\hline Semi IPNs (9) & -81 \\
\hline B) PDMS (8) & -117 \\
\hline $\mathrm{PM}(5)$ & -75 \\
\hline Semi IPNs (10) & -97 \\
\hline C) PDMS (8) & -117 \\
\hline PM (6) & -76 \\
\hline Semi IPNs (11) & -99 \\
\hline D) PDMS (8) & -117 \\
\hline PM (7) & -67 \\
\hline Semi IPNs (12) & -85 \\
\hline
\end{tabular}


From the resultats presented in Table 2, neat PDMS presents a thermal transition temperature at $-117^{\circ} \mathrm{C}$, which is close to the experimental value reported in the literature [26]. For the modifier polymers, the Tgs values of the PEO (4), PPO (5), PEO-monolaurate (6) and Breaker (7) are found to be at $-63,-75,-76$ and $-67{ }^{\circ} \mathrm{C}$, respectively. These values are in accordance with the $\mathrm{Tg}$ reported in the literature [26-27].

In addition we have observed that the Tg value of the neat PDMS is different and lower than the values of Tgs obtained from DSC results of the semi-IPNs phases (9-12). An effective entrapment of PEO derivatives chains in PDMS network might inhibit their mobility in the structure. Therefore, the segmental motion of polymer chains is inhibited leading to increase glass transition temperature [28]. Therefore, the presence of a single Tg indicates the perfect miscibility and homogeneity between PDMS and the PEO-dervivatives polymers. These clearly confirms that these results arose from the existence of homogenous, miscible and highly crosslinked three dimensional semi-interpenetrating networks.

SEM images of neat PDMS and of modified PDMS phase 12 are presented in Figure 4. A total homogeneity of the surface of both PDMS phases, without any agglomeration in modified PDMS phase 12.

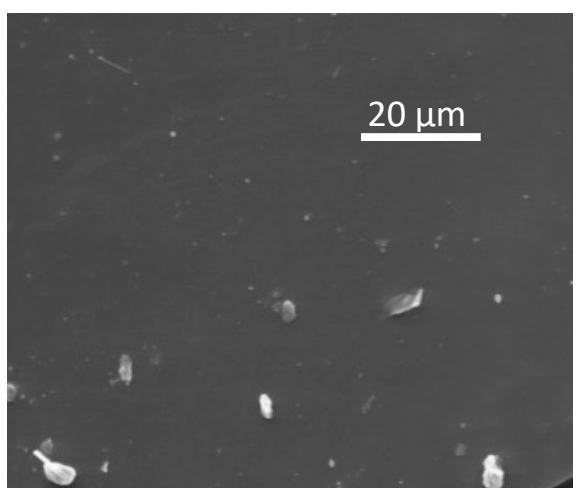

(a)

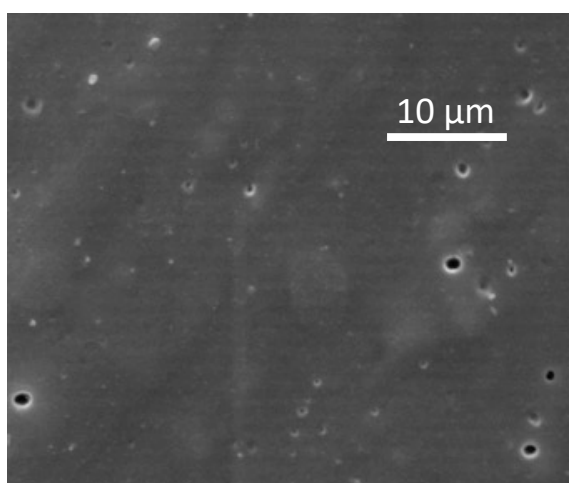

(b)

Figure 4. SEM images of (a) neat PDMS (b) modified PDMS phase 12

The contact angles measured with water, on neat PDMS and on modified PDMS phase 12 surfaces are presented in Figure 5. The wettability of the modified PDMS phase 12 is highly improved by the insertion of Beaker $2(30 \%)$ which will then improve the adsorption of more polar phenol compounds. 


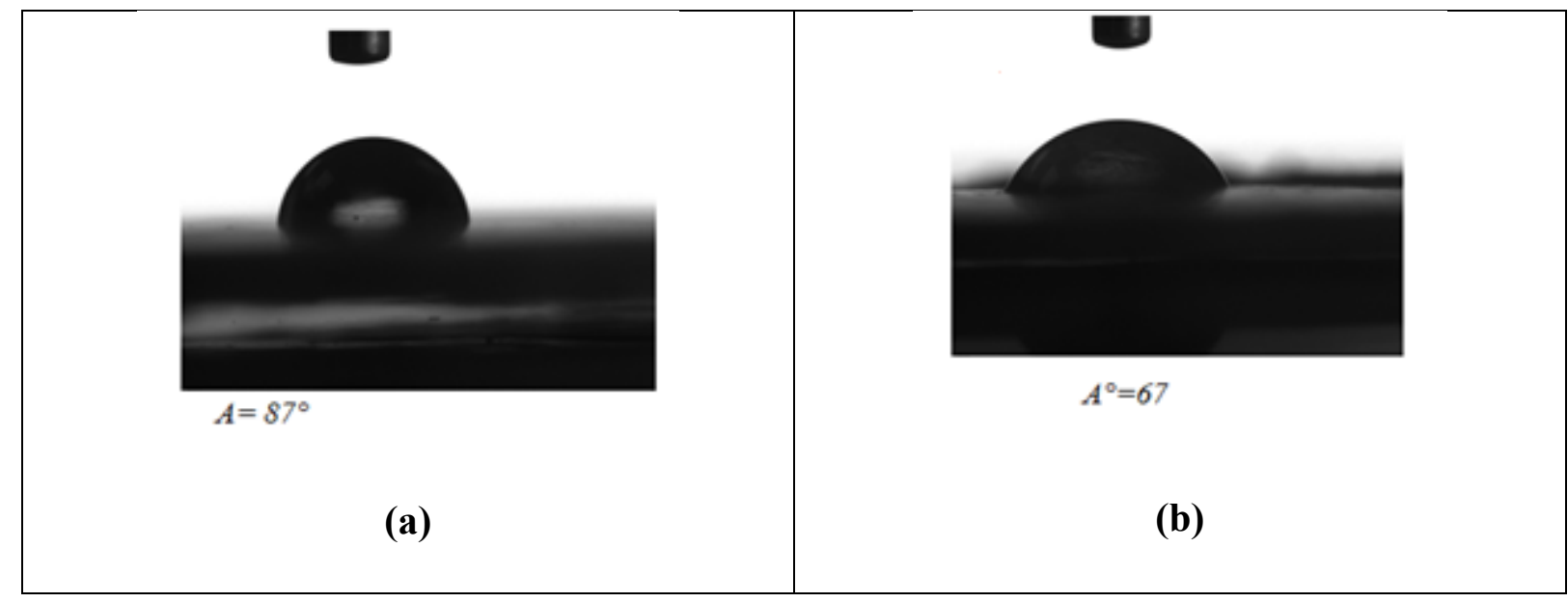

Figure 5. Contact angle measurements of water on (a) neat PDMS (b) modified PDMS phase 12 surfaces.

\section{2- Extraction procedures}

The high polarity of specific contaminants in water is considered as the main problem of a limited extraction capacity of conventional extraction techniques (eg, SBSE or SPME techniques) basing on neat PDMS [8]. As it can be seen in Figure 6, series of phenols compounds; as target analytes, (used for the preparation of doped aqueous solutions) the decreasing of the logarithm of the octanol/water partition coefficient (Log Kow) indicates a more hydrophile character of these molecules (eg, 4-hydroxybenzoic acid, caffeic-acid) and consequently an opposite affinity with PDMS solid phases.

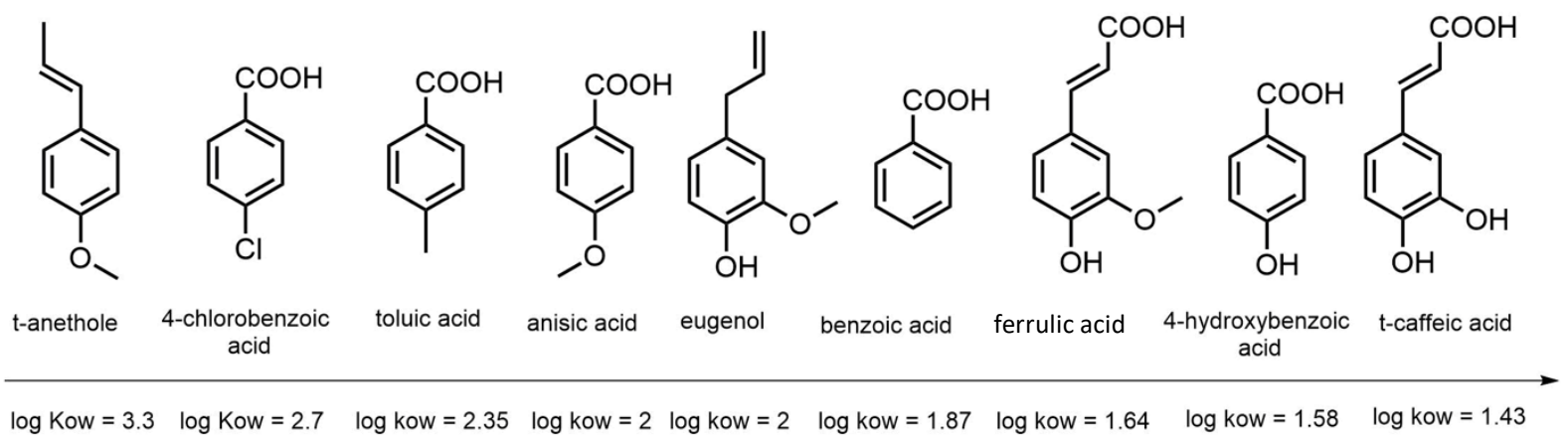

Figure 6. Chemical structures and log Kow values of the targeted phenolic analytes. 
HPLC-DAD was used for the detection of these phenolic compounds with an initial concentration of $1 \mathrm{ppm}$. The figure of merit for all the target molecules is the following one: LOD $0.1 \mathrm{ppm}$, LOQ $0.5 \mathrm{ppm}$, linear range $0.1 \mathrm{ppm}$ to $200 \mathrm{ppm}$, RSD $1 \%$.

\section{2-a- Extraction of the phenolic compounds as target molecules:}

\section{Effect of the salting out of the phenolic compound solutions on the extraction rate}

The salting-out effect is commonly used to maximize the extraction efficiency in analytical procedures by adding salt to water samples [29]. In fact, the addition of inert salts would enhance the transfer of polar analytes towards the acceptor phase by decreasing the solubility of these analytes in the aqueous sample solution. This study of the salting-out effect on the prepared solutions of the phenolic compounds with higher polarities (Figure 6) was conducted with the neat PDMS (phase 8).

A first extraction test was carried out using solutions without sodium chloride as reference. Then two subsequent extraction tests were performed following the addition of $10 \%$ and $30 \%$ $\mathrm{NaCl}$, respectively. After repeating 3 times each extraction experiment, an RSD was found to be $5 \%$.

The results, shown in Figure 7, indicate that the adsorption efficiency, obtained for salt free solution, of polar molecules (p-hydroxy, caffeic, ferrulic, and benzoic acids) does not exceed $10 \%$ compared to non-polar ones which can reach nearly a yield of $100 \%$ (t-anethol). However, the addition of $10 \%$ of sodium chloride slightly increased the adsorption efficiency of both polar and non polar molecules. Moreover, the addition of $30 \%$ of sodium chloride can improve remarkably the adsorption efficiency which reached up to $60 \%$ for the ferrulic acid case whereas it was less than $20 \%$ with the addition of $10 \%$ of $\mathrm{NaCl}$. 


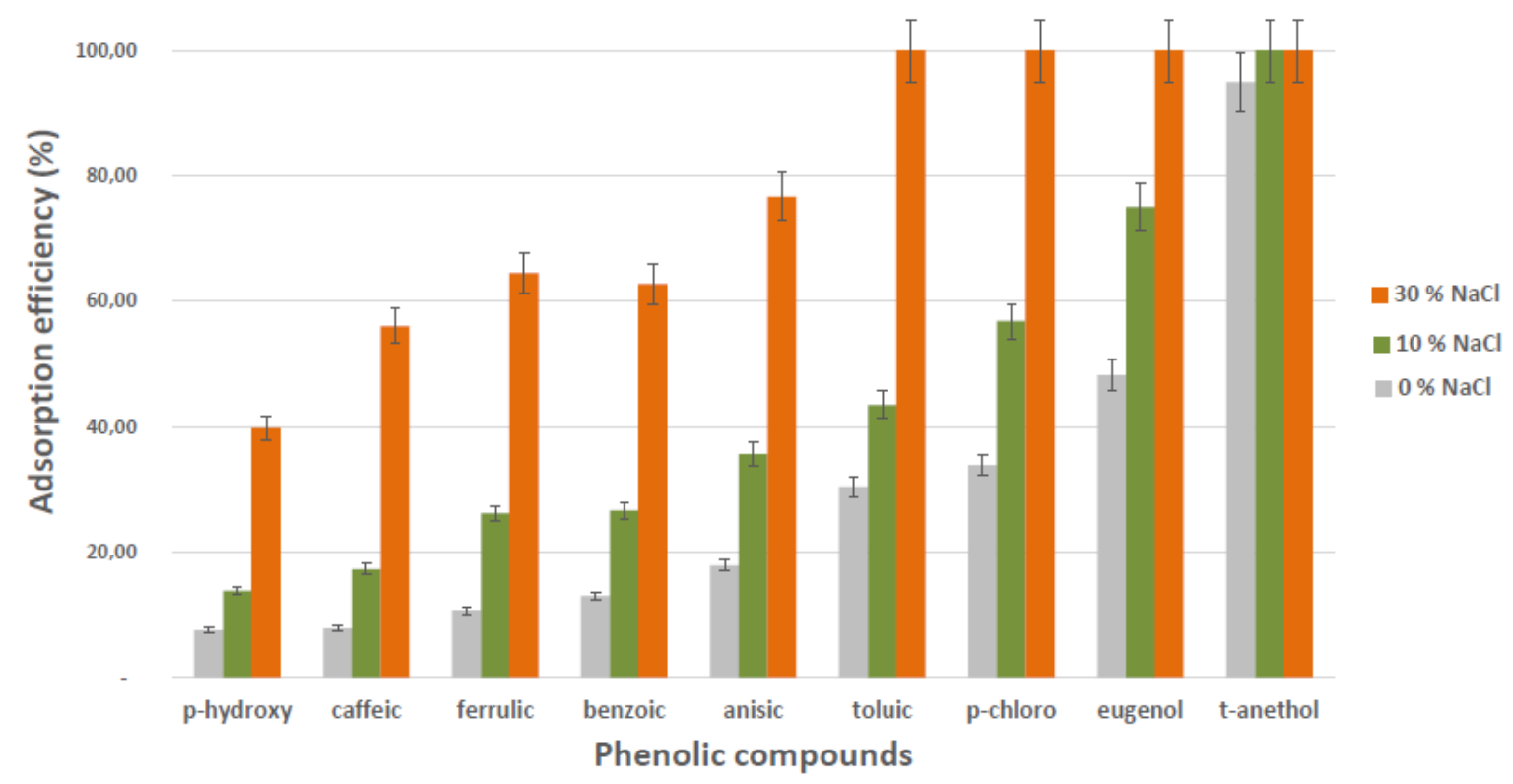

Figure 7. Salting-out effects obtained in $\mathrm{NaCl}$ solutions with PDMS (8) - Time of equilibration: $5 \mathrm{~h}$

From the salting-out effect study, it can be concluded that even though the use of the neat PDMS 8 (solid phase), the addition of $30 \%$ of sodium chloride has allowed a significant modification of the ionic strength of the solutions resulting in a reduced solubility of these components in water and consequently an efficient transfer of polar analytes from the aqueous solution to the sorptive phase. All the following extraction experiments will be performed using the different phases, the phenolic compound solutions will contain $30 \% \mathrm{NaCl}$ in order to maximize the adsorption efficiency of the polar molecules as it was revealed previously.

\section{Effect of the structure and of the percentage of PM on the adsorption efficiency}

An extraction optimization was carried out for all prepared PDMS solid phases: 8 (neat PDMS phase considered as reference) and 9-12 (table 1), neat PDMS with the addition of diverse amounts of polymer modifiers (20\% and 30\%). A kinetic study was carried out by varying the equilibrium durations from $1 \mathrm{~h}$ up to $24 \mathrm{~h}$. After repeating 3 times each extraction experiment, the RSD was found to be 5\%. The adsorption efficiency of these novel PDMS phases and the determination of the optimum parameters were assessed by calculating the recoveries from aqueous solutions doped with the target compounds. From the preliminary results of phenol adsorption (Table 3) it has been marked that:

- The highest adsorption efficiency of the phenol molecules was obtained with the addition of 20 and $30 \%$ of PM in the PDMS phase. However a further increase in the amount of the PM 
does not improve the adsorption efficiency and, on the other hand, the linear PEO chains are found to be excluded from the network.

- The obtained adsorption efficiency after $24 \mathrm{~h}$ were similar to those found at $5 \mathrm{~h}$, therefore, only the two equilibium durations: $1 \mathrm{~h}$ and $5 \mathrm{~h}$ were reported. This leads to conclude that equilibrium duration of 5 hours is sufficient.

Table 3: Effect of the modified PDMS phases on the adsorption efficiency (\%) of the phenolic compounds for two different duration times of equilibration ( $1 \mathrm{~h}$ and $5 \mathrm{~h}$ )

According to the adsorption efficiency values of both polar and non-polar molecules and independently on the required time or the composition of each PDMS phase, a distinct difference can be noticed. In fact, it can be observed that in the case of the extraction of tanethol (non polar) that its adsorption efficiency is in the range of $80-100 \%$ compared to the p-hydroxybenzoïc acid (polar phenol) which shows an adsorption efficiency ranging from 4 up to $70 \%$. In fact, this result can be expected and the non-polar molecules tend to be easily removed since they have the same affinity with the surface of the PDMS phase.

On the other hand, and focusing on the reactivity of the novel modified PDMS phases (9-12), it was observed that the lowest extraction rates (4-20\%) were reported while using neat PDMS solid phase 8 particularly for the most polar ones (eg, p-hydroxybenzoic, caffeic, ferrulic and benzoic acids). Nevertheless, the novel PDMS phases (9-12) have shown a noticeable improved adsorption efficiency since their selectivity towards polar molecules were reinforced by the polar character of PEO chains. Moreover, the increase of the adsorption efficiency depends on the PM percentage added to the conventional PDMS. Indeed, in all cases the rate of the extracted phenolic compounds increases with time, however, a duration of five hours represents the optimal time which allows a maximal adsorption efficiency of all these entities to be reached. It was shown that the increase of the percentage of the PM can result in an increase of the adsorption efficiency. Thus, a presence of $30 \%$ of PM in the neat PDMS phase can allow a higher adsorption efficiency than it can be obtained by $20 \%$ of PM (Table 3). In order to reveal how each PM (4-7) added to the PDMS solid phase affects the extraction procedures, the adsorption efficiency of the various phenolic molecules were calculated under the following optimal conditions: $30 \% \mathrm{NaCl}, 5 \mathrm{~h}, 30 \% \mathrm{PM}$ and are presented in Figure 8. 


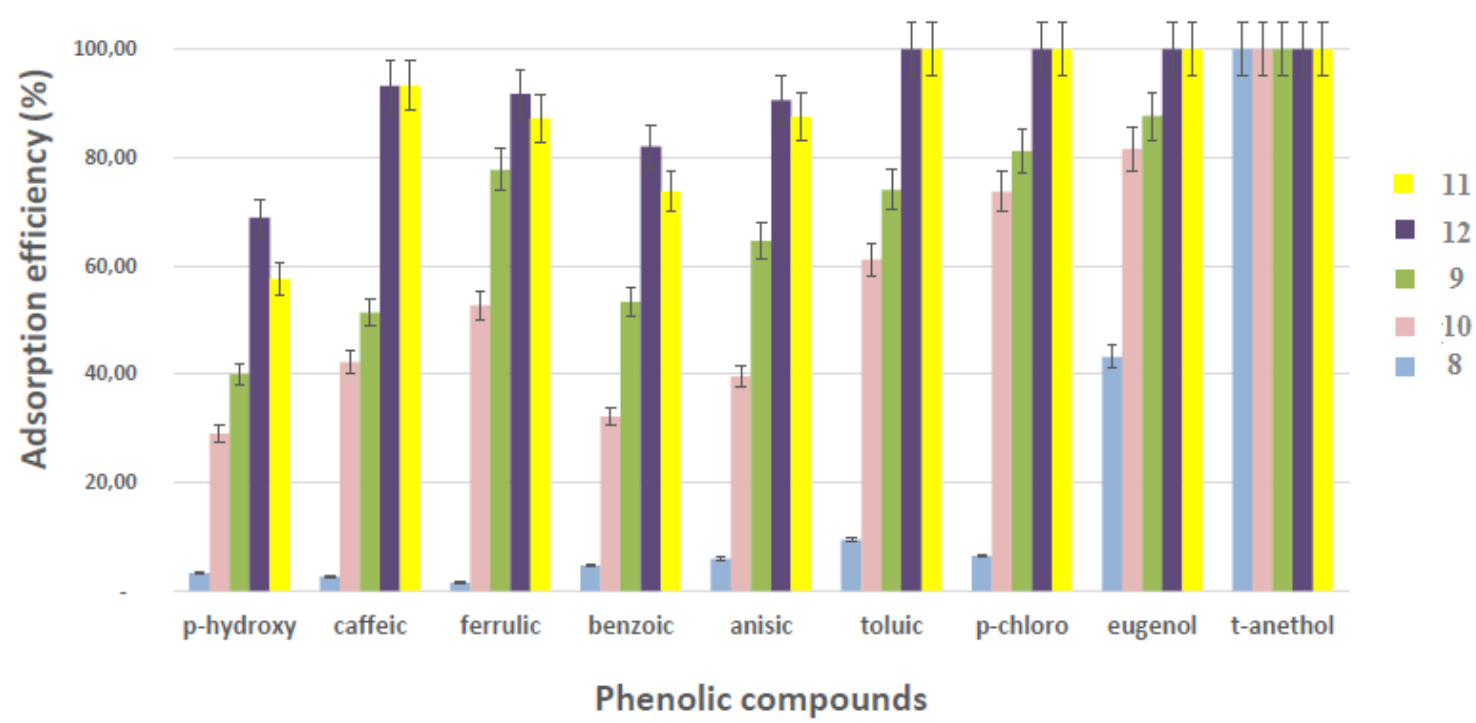

Figure 8. Adsorption efficiency of the phenolic compounds on PDMS (8) and the different modified PDMS phases $(9,10,11,12)$ for $5 \mathrm{~h}$ of equilibration time.

As previously mentioned, all novel solid PDMS phases (9-12), showed a clear enhancement of the extraction of the polar and non-polar pollutants against conventional PDMS phase 8 . This is mainly due to the polar character of PEO chains which can allow a better ability to extract the most polar molecules. However, if we compare the phenol adsorption efficiency of phase 9 and phase 10, respectively, it can be noted that the highest adsorption efficiency was observed when using phase 9 (with PEO as PM 4). As for example, in the case of ferrulic acid, the recovery yield obtained using phase $\mathbf{1 0}$ was $70 \%$ whereas it was increased to $80 \%$ with the solid adsorbent phase 9. Although both PMs PEO 4 and PPO 5 share the same molar mass of 400 g.mol ${ }^{-1}$, their effects on adsorption efficiency was different. This difference might result on the chemical structure of the repeating unit of PPO 5 which contains a pendant methyl group responsible of its reduced polarity compared to PEO 4 leading, thus, to a lower adsorption efficiency. Based on these results, a combination of the hydrophobic character of 5 and polar character of 4 to obtain a copolymer matrix (Breaker 2: PM7) and its addition in PMDS phase 12 as a polymer modifier (7), was suggested. Finally, for the case of the adsorption efficiency of phase 11, using alkyl polyethylene oxide (6) as polymer modifier, this latter has in turn a similar extraction effect as $\mathbf{1 2}$ since they have both aliphatic and alkoxyl segments which confer to the PDMS phase a most suitable affinity for polar and nonpolar molecules. 


\section{Reusability cycling}

Stability and reproductibility are noteworthy features of the sorbents, then it is necessary to study their regeneration and reusability. Regeneration experiments were performed by a series of successive extractions. Then, a desorption process using methanol as washing solvent, due to its polarity, low volatilty and its capacity to dissolve the pollutants, was conducted. When the equilibrium was reached after $5 \mathrm{~h}$ of contact with the pollutants, the PDMS phases (11 or 12) were washed with $10 \mathrm{~mL}$ of methanol for 40 minutes, at room temperature. It was then washed with deionized water and dried to be reused for the next cycle. Table 4 shows the reusability study of the two most efficient PDMS phases (11 and 12), for 10 consecutive cycles (adsorption/desorption).

Table 4. Adsorption/desorption cycles with the PDMS phases 11 and 12 after 5 hours of contact with the polluants and washed with $10 \mathrm{~mL}$ of methanol for 40 minutes and then 5 hours of contact with the target polyphenols

The data showed that phase 11 exhibits a good stability for 6 cycles, the removal efficiency decreased $10 \%$ compared to cycle 1 for the most hydrophilic pollutants. Although, it does not decrease for the hydrophobic ones. After 10 cycles, the adsorption efficiency of the phase 11, was not completely regenerated under the chosen regenerating conditions, especially for the most hydrophilic pollutants. However, the adsorption efficiency decreased slightly with number of cycles for the most hydrophobic pollutants from $100 \%$ to 91 or $79 \%$ whereas it decreased more significantly for the hydrophilic molecules: it decreased from $96 \%$ to $42 \%$ for cafeic acid after 10 cycles. Nevertheless, the results presented in Table 3, show that the phase 12 exhibits a good recyclability after 10 cycles. However, the adsorption efficiency was reduced by 10 percent from the 1 st cycle to the 10th cycle for all hydrophylic and hydrophobic tested pollutants.

\section{Comparison of the adsorption efficiency of the prepared PDMS phases with those of published polymeric phases.}

Table 5. Comparison of the adsorption efficiency of the prepared PDMS phases with those of published polymeric phases.

\begin{tabular}{|l|l|l|l|}
\hline Polymeric phase & Pollutant & Adsorption efficiency & References \\
\hline
\end{tabular}




\begin{tabular}{|l|c|c|c|c|}
\hline & & Cycle 1 & Cycle 5 & \\
\hline Silica grafted with CTABr & 4-hydroxybenzoic acid & $56 \%$ & & {$[30]$} \\
\hline $\begin{array}{l}\text { poly(ether pyridine) based } \\
\text { on BPA }\end{array}$ & 4-hydroxybenzoic acid & $26 \%$ & & {$[31]$} \\
\hline $\begin{array}{l}\text { poly(ether pyridine) based } \\
\text { on isosorbide }\end{array}$ & 4-hydroxybenzoic acid & $96 \%$ & $63 \%$ & {$[31]$} \\
\hline $\begin{array}{l}\text { PDMS } \\
\text { PDMS + 30\% Breaker }\end{array}$ & 4-hydroxybenzoic acid & $69 \%$ & $65 \%$ & This work \\
\hline
\end{tabular}

As presented in Table 5, 4-hydroxybenzoic acid (log Know $=1.58)$ presents higher adsorption efficiency on 30\% Breaker modified PDMS (69\%), compared to neat PDMS (7\%), as shown in this work. Higher adsorption efficiency was found for a biosourced poly(ether pyridine) (96\%) compared to BPA based poly(ether pyridine) (26\%) [31]. Lower adsorption efficiency was found for silica grafted with $\mathrm{CTABr}$ (cetyltrimethylammonium bromide) (56\%) [30] than for a biosourced poly(ether pyridine) and for 30\% PEO/PPO modified PDMS.

About the recycling of the adsorbent phases, a lost of $5.8 \%$ of the adsorption efficiency was observed after 5 adsorption/desorption cycles for 30\% PEO/PPO modified PDMS whereas a lost of $34 \%$ was observed 5 cycles for a biosourced poly(ether pyridine) [31].

\section{Conclusion :}

In this work a new class of polymer for adsorption process application based on PDMS semiIPNs by the versatile hydrosilylation crosslinking reaction was successfully developed. They present a high homogeneity and a more hydrophilic character than neat PDMS. Under the optimal extraction conditions the novel solid adsorbent phases showed an excellent extraction performance for removing polar phenolic analytes from standard aqueous solutions. The highest adsorption efficiencies were reached with modified PDMS phases containing 30\% of $\mathrm{PM}$ and an extraction duration of $5 \mathrm{~h}$. One of the more polar compound 4-hydroxybenzoic acid was found to present an adsorption efficiency of $69 \%$ on $30 \%$ PEO/PPO modified PDMS whereas it was only $7 \%$ for neat PDMS. Moreover five adsorption/desorption cycles led to a 
lost of $5.8 \%$ of the adsorption efficiency, showing a good stability of these PDMS-based IPN phases. These phases could then be used as new solid phases suitable for SBSE and SPME devices.

Funding: We would like to acknowledge the financial support of CAMPUS-FRANCE and the French Embassy in Tunisia (Dr. Pierre Durand De Ramefort) for the SSHN grant, of the High Ministry of Education and Research in Tunisia for doctoral grant and European Commission for TUNWIN project Grant 952306. Anne Bonhomme is acknowledged for RAMAN measurements.

\section{References:}

[1] P. Schwarzenbach, T. Egli, T.B. Hofstetter, U. Von Gunten, B. Wehrli, Global water pollution and human health, Ann. Rev. Environ. Resour. 35 (2010) 109-136, https://doi.org/10.1146/annurevenviron-100809-125342.

[2] M. Hendryx, J. Conley, E. Fedorko, J. Luo, M. Armistead, Permitted water pollution discharges and population cancer and non-cancer mortality: toxicity weights and upstream discharge effects in US rural-urban areas, Int. J. Health Geogr. 9 (2012) 1-15, https://doi.org/10.1186/1476-072X-11-9. [3] Y. Lu, S. Song, R. Wang, Z. Liu, J. Meng, A.J. Sweetman, A. Jenkins, R.C. Ferrier, H. Li, W. Luo, T. Wang, Impacts of soil and water pollution on food safety and health risks in China, Environ. Int. 77 (2015) 5-15, https://doi.org/10.1016/i. envint.2014.12.010.

[4] I. Ali, V.K. Gupta, Advances in water treatment by adsorption technology, Nat. Protoc. 1 (2006) 2661-2667. https://doi.org/10.1038/nprot.2006.370.[5]Y.T. Chong, M. Mohd, N.M. Tahir, S.H. Loh, A green solvent holder in electro-mediated microextraction for the extraction of phenols in water, Talanta 176 (2018) 558-564. https://doi.org/10.1016/j.talanta.2017.08.068.

[6] K.D. Buchholz, J. Pawliszyn, Optimization of Solid-Phase Microextraction Conditions for Determination of Phenols, Anal. Chem. 66 (1994) 160-167. https://doi: 10.1021/ac00073a027.

[7] A. Cortéjade, A. Buleté, L. Prouteau, S. Chatti, C. Cren, E. Vulliet, Development and optimisation of home-made stir bar sorptive extraction for analysis of plastic additives: application in human urine, Anal. Methods, 9 (2017) 3549-3560. https://doi.org/10.1039/C7AY00696A.

[8] J.M.F. Nogueira, Novel sorption-based methodologies for static microextraction analysis : A review on SBSE and related techniques, Anal. Chim. Acta. 757 (2012) 1-10.

https://doi.org/10.1016/j.aca.2012.10.033.

[9] J.E. Mark, Some Interesting Things about Polysiloxanes, Acc. Chem. Res. 37 (2004) 946-953. https://doi.org/10.1021/ar030279z.

[10] M.J. Owen, Properties and Applications of Silicones in Advances in Silicones and SiliconeModified Materials, Eds D.A. Schiraldi, ACS Symposium Series, Vol 1051, 2010 pp. 13-18.

DOI: 10.1021/bk-2010-1051.ch002.

[11] S. Seethapathy, T. Górecki, Analytica Chimica Acta Applications of polydimethylsiloxane in analytical chemistry : A review, Anal. Chim. Acta. 750 (2012) 48-62.

https://doi.org/10.1016/j.aca.2012.05.004.

[12] H. Faraji, S.W. Husain, M. Helalizadeh, $\beta$-Cyclodextrin-bonded silica particles as novel sorbent 
for stir bar sorptive extraction of phenolic compoundsJ. Chromatogr. Sci. 49 (2011) 482-487. [13] C. Yu, Z. Yao, B. Hu, Preparation of polydimethylsiloxane/_-cyclodextrin/divinylbenzene coated "dumbbell-shaped" stir bar and its application to the analysis of polycyclic aromatic hydrocarbons and polycyclic aromatic sulfur heterocycles compounds in lake water and soil by high performance liquid chromatography Anal. Chim. Acta 641 (2009) 75-82.https://doi.org/0.1016/j.aca.2009.03.031 [14] C. Yu, B. Hu, Sol-gel polydimethylsiloxane/poly(vinylalcohol)-coated stir bar sorptive extraction of organophosphorus pesticides in honey and their determination by large volume injection GC. J. Sep. Sci. 32 (2009) 147-153.

[15] S. Chatti, H. Casabianca, Novel extraction phases based on PDMS derivatives (SBSE technique) for sample preparation, Spectra Analyse, 306 (2015) 39-44.

[16] A. Mandal, D. Chakrabarty, Characterization of nanocellulose reinforced semiinterpenetrating polymer network of poly(vinyl alcohol) \& polyacrylamide composite films, Carbohydr. Polym. 134 (2015) 240-250. https://doi.org/10.1016/j.carbpol.2015.07.093.

[17] V.A. Online, W. Chu, J. Li, S. Kuo, From flexible to mesoporous polybenzoxazine resins templated by poly(ethylene oxide- $b$ - $\varepsilon$-caprolactone) copolymer through reaction induced microphase separation mechanism, RSC Advances, 3 (2013) 6485-6498. https://doi.org/10.1039/c3ra23447a.

[18] N. Rodkate, U. Wichai, B. Boontha, M. Rutnakornpituk, Semi-interpenetrating polymer network hydrogels between polydimethylsiloxane / polyethylene glycol and chitosan, Carbohydr. Polym. 81 (2010) 617-625. https://doi.org/10.1016/i.carbpol.2010.03.023.

[19] T. Chabbah, H. Abderrazak, P.S. Martin, H. Casabianca, H.R. Kricheldorf, S. Chatti, Synthesis of Glux based polymers for removal of benzenederivatives and pesticides from water, Polym. Adv. Technol. (2020). https://doi: 10.1002/pat4953.

[20] E. Ratsimihety, B. Boutevin, F. Guida-pietrasanta, Synthesis of Photocrosslinkable Fluorinated Polydimethylsiloxanes : Direct Introduction of Acrylic Pendant Groups via Hydrosilylation, J. Polym. Sci. A Polym. Chem. 38 (20) (2000) 3722-3728. https://doi.org/10.1002/1099-0518.

[21] A. Nyczyk, C. Paluszkiewicz, M. Hasik, M. Cypryk, P. Pospiech, Vibrational Spectroscopy Crosslinking of linear vinylpolysiloxanes by hydrosilylation - FTIR spectroscopic studies, Vib. Spectrosc. 59 (2012) 1-8. https://doi.org/10.1016/i.vibspec.2012.01.002.

[22] N. Risangud, Z. Li, A. Anastasaki, P. Wilson, D.M. Haddleton, Hydrosilylation as an efficient tool for polymer synthesis and modification with methacrylates, RSC Adv., 5 (2015) 5879-5885. https://doi.org/10.1039/C4RA14956D.

[23] H. Xiao, Z.H. Ping, J.W. Xie, T.Y. Yu, The Synthesis and Morphology of Semi-Interpenetrating Polymer Networks Based on Polyurethane - PolydiMethysiloxane System, J. Polym. Sci.: Part A: Polym. Chem., 28 (1990) 585-594. https://doi: 10.1002/pola.1990.080280310.

[24] C. Erbil, E. Kazancıo, N. Uyanık, EUROPEAN POLYMER Synthesis, characterization and thermoreversible behaviours of poly ( dimethyl siloxane )/ poly ( $\mathrm{N}$-isopropyl acrylamide ) semiinterpenetrating networks, Eur. Polym. J., 40 (2004) 1145-1154.

https://doi.org/10.1016/j.eurpolymj.2003.12.024.

[25] F.A.B. Silva, F.H. Florenzano, F.L. Pissetti, Synthesis and characterization of semiinterpenetrating polymer network based on poly ( dimethylsiloxane ) and poly [ 2- ( dimethylamino ) ethyl methacrylate ], J. Sol-Gel Sci. Technol., 72 (2014) 227-232. https://doi.org/10.1007/s10971-0143320-x.

[26] M. Rutnakornpituk, P. Ngamdee, P. Phinyocheep, Synthesis, characterization and properties of chitosan modified with poly ( ethylene glycol )- polydimethylsiloxane amphiphilic block copolymers, Polymer, 46 (2005) 9742-9752. https://doi.org/10.1016/j.polymer.2005.08.051. 
[27] P. Sung, C.Y. Lin, Polysiloxane modified epoxy polymer network. II. Dynamic mechanical behavior of multicomponent graft-IPNs (Epoxy/polysiloxane/polypropylene glycol), European polymer journal, 33 (1997) 231-233. https://doi.org/10.1016/S0014-3057(96)00215-7.

[28] C. Chiu, Y. Yen, S. Kuo, H. Chen, F. Chang, Complicated phase behavior and ionic conductivities of PVP- co -PMMA-based polymer electrolytes, Polymer, 48 (2007). https://doi.org/10.1016/j.polymer.2006.12.059.

[29] S. Endo, A. Pfennigsdorff, K. Goss, Salting-Out Effect in Aqueous NaCl Solutions: Trends with Size and Polarity of Solute Molecules, Environ. Sci. Technol., 46 (2012) 1496-1503. https://doi : 10.1021/es203183z.

[30] M. Makhlouf, O. Bouchher, M.S. Mohamed, B. Khaled, Adsorption of Phenol and 4Hydroxybenzoic Acid onto Functional Materials, International Journal of Chemical and Molecular Engineering 11 (2017) 209-213.

[31] M. Gomri, H. Abderrazak, T. Chabbah, R. Souissi, P. Saint-Martin, H. Casabianca, S. Chatti, R. Mercier, A. Errachid, M. Hammami, Nicole Jaffrezic-Renault. Adsorption characteristics of aromatic pollutants and their halogenated derivatives on bio-based poly (ether-pyridine)s. Journal of Environmental Chemical Engineering 8 (2020) 104333. https://doi.org/10.1016/j.jece.2020.104333 
Table 3: Effect of the modified PDMS phases on the adsorption efficiency (\%) of the phenolic compounds for two different duration times of equilibration ( $1 \mathrm{~h}$ and $5 \mathrm{~h})$

\begin{tabular}{|c|c|c|c|c|c|c|c|c|c|c|c|c|c|c|c|c|c|c|}
\hline \multirow{3}{*}{$\begin{array}{c}\text { PDMS phases } \\
\% \text { PM (4-7)* } \\
\text { Extraction Time (hours) }\end{array}$} & \multirow{2}{*}{\multicolumn{2}{|c|}{$\begin{array}{c}8^{* *} \\
-\end{array}$}} & \multicolumn{4}{|c|}{$9 * *$} & \multicolumn{4}{|c|}{$10^{* * *}$} & \multicolumn{4}{|c|}{$11^{* *}$} & \multicolumn{4}{|c|}{$12 * *$} \\
\hline & & & \multicolumn{2}{|c|}{$4(20 \%)$} & \multicolumn{2}{|c|}{$4(30 \%)$} & \multicolumn{2}{|c|}{$5(20 \%)$} & \multicolumn{2}{|c|}{$5(30 \%)$} & \multicolumn{2}{|c|}{$6(20 \%)$} & \multicolumn{2}{|c|}{$6(30 \%)$} & \multicolumn{2}{|c|}{$7(20 \%)$} & \multicolumn{2}{|c|}{$7(30 \%)$} \\
\hline & 1 & 5 & 1 & 5 & 1 & 5 & 1 & 5 & 1 & 5 & 1 & 5 & 1 & 5 & 1 & 5 & 1 & 5 \\
\hline hudid & $4.21 \pm$ & $6.99 \pm$ & $24.66 \pm$ & $24.24 \pm$ & $34.13 \pm$ & $34.14 \pm$ & $18.39 \pm$ & $27.04 \pm$ & $32.18 \pm$ & $33.7 \pm$ & $41.4 \pm$ & $47.31 \pm$ & $46.46 \pm$ & $50.79 \pm$ & $44.35 \pm$ & $60.38 \pm$ & $50.02 \pm$ & $68.91 \pm$ \\
\hline 1y aroxyoenzolc acid & 0.21 & 0.35 & 1.23 & 1.21 & 1.71 & 1.71 & 0.92 & 1.35 & 1.61 & 1.69 & 2.07 & 2.37 & 2.32 & 2.54 & 2.22 & 3.02 & 2.50 & 3.45 \\
\hline$t$ - caffeic acid & $\begin{array}{c}10.25 \pm \\
0.51\end{array}$ & $\begin{array}{c}12.75 \pm \\
0.64\end{array}$ & $\begin{array}{c}49.54 \pm \\
2.48\end{array}$ & $\begin{array}{c}54.9 \pm \\
2.75\end{array}$ & $\begin{array}{c}51.61 \pm \\
2.58\end{array}$ & $\begin{array}{c}61.69 \pm \\
3.08\end{array}$ & $\begin{array}{c}30.72 \pm \\
1.54\end{array}$ & $\begin{array}{c}49.98 \pm \\
2.50\end{array}$ & $\begin{array}{c}47.38 \pm \\
2.37\end{array}$ & $\begin{array}{c}58.92 \pm \\
2.95\end{array}$ & $\begin{array}{c}52.11 \pm \\
2.61\end{array}$ & $\begin{array}{c}58.14 \pm \\
2.91\end{array}$ & $\begin{array}{c}66.88 \pm \\
3.34\end{array}$ & $\begin{array}{c}96.06 \pm \\
4.80\end{array}$ & $\begin{array}{c}64.33 \pm \\
3.22\end{array}$ & $\begin{array}{c}93.04 \pm \\
4.65\end{array}$ & $\begin{array}{c}70.02 \pm \\
3.50\end{array}$ & $\begin{array}{c}93.24 \pm \\
4.66\end{array}$ \\
\hline ferrulic acid & $\begin{array}{c}17.56 \pm \\
0.88\end{array}$ & $\begin{array}{c}19.55 \pm \\
0.98\end{array}$ & $\begin{array}{c}71.63 \pm \\
3.58\end{array}$ & $\begin{array}{c}71.79 \pm \\
3.59\end{array}$ & $\begin{array}{c}79.7 \pm \\
3.99\end{array}$ & $\begin{array}{c}81.43 \pm \\
4.07\end{array}$ & $\begin{array}{c}50.84 \pm \\
2.54\end{array}$ & $\begin{array}{c}62.88 \pm \\
3.14\end{array}$ & $\begin{array}{c}64.81 \pm \\
3.24\end{array}$ & $\begin{array}{c}69.80 \pm \\
3.49\end{array}$ & $\begin{array}{c}65.67 \pm \\
3.28\end{array}$ & $\begin{array}{c}73.21 \pm \\
3.66\end{array}$ & \begin{tabular}{|c}
$71.36 \pm$ \\
3.57
\end{tabular} & $\begin{array}{c}91.70 \pm \\
4.59\end{array}$ & $\begin{array}{c}78.29 \pm \\
3.91\end{array}$ & \begin{tabular}{|c|}
$92.63 \pm$ \\
4.63
\end{tabular} & \begin{tabular}{|c}
$77.49 \pm$ \\
3.87
\end{tabular} & $\begin{array}{c}91.72 \pm \\
4.59\end{array}$ \\
\hline benzoic acid & $\begin{array}{c}14.11 \pm \\
0.71\end{array}$ & $\begin{array}{c}15.96 \pm \\
0.80\end{array}$ & $\begin{array}{c}42.12 \pm \\
2.11\end{array}$ & $\begin{array}{c}51.86 \pm \\
2.59\end{array}$ & $\begin{array}{c}56.8 \pm \\
2.48\end{array}$ & $\begin{array}{c}67.27 \pm \\
3.36\end{array}$ & $\begin{array}{c}33.07 \pm \\
1.65\end{array}$ & $\begin{array}{c}45.11 \pm \\
2.26\end{array}$ & $\begin{array}{c}39.08 \pm \\
1.95\end{array}$ & $\begin{array}{c}47.06 \pm \\
2.35\end{array}$ & $\begin{array}{c}64.16 \pm \\
3.21\end{array}$ & $\begin{array}{c}66.99 \pm \\
3.35\end{array}$ & $\begin{array}{c}65.53 \pm \\
3.28\end{array}$ & \begin{tabular}{|c}
$77.97 \pm$ \\
3.90
\end{tabular} & $\begin{array}{c}75.73 \pm \\
3.79\end{array}$ & $\begin{array}{c}79.97 \pm \\
4.00\end{array}$ & \begin{tabular}{|c|}
$75.49 \pm$ \\
3.77
\end{tabular} & $\begin{array}{c}82.04 \pm \\
4.10\end{array}$ \\
\hline anisic acid & $\begin{array}{c}49.36 \pm \\
2.47\end{array}$ & $\begin{array}{c}55.87 \pm \\
2.79\end{array}$ & $\begin{array}{c}52.18 \pm \\
2.61\end{array}$ & $\begin{array}{c}66.19 \pm \\
3.31\end{array}$ & $\begin{array}{c}67.53 \pm \\
3.38\end{array}$ & $\begin{array}{c}80.28 \pm \\
4.01\end{array}$ & $\begin{array}{c}38.73 \pm \\
1.94\end{array}$ & $\begin{array}{c}57.03 \pm \\
2.85\end{array}$ & $\begin{array}{c}48.78 \pm \\
2.44\end{array}$ & $\begin{array}{c}91.96 \pm \\
4.60\end{array}$ & $\begin{array}{c}78.55 \pm \\
3.93\end{array}$ & $\begin{array}{c}81.99 \pm \\
4.10\end{array}$ & $\begin{array}{c}78.31 \pm \\
3.92\end{array}$ & $\begin{array}{c}85.99 \pm \\
4.30\end{array}$ & $\begin{array}{c}86.55 \pm \\
4.33\end{array}$ & $\begin{array}{c}89.79 \pm \\
4.49\end{array}$ & $\begin{array}{c}83.69 \pm \\
4.18\end{array}$ & $\begin{array}{c}90.57 \pm \\
4.53\end{array}$ \\
\hline toluic acid & $\begin{array}{c}47.01 \pm \\
2.35\end{array}$ & $\begin{array}{c}49.21 \pm \\
2.46\end{array}$ & $\begin{array}{c}64.23 \pm \\
3.21\end{array}$ & $\begin{array}{c}82.26 \pm \\
4.11\end{array}$ & $\begin{array}{c}76.79 \pm \\
3.84\end{array}$ & $\begin{array}{c}91.04 \pm \\
4.55\end{array}$ & $\begin{array}{c}62.55 \pm \\
3.13\end{array}$ & $\begin{array}{c}81.35 \pm \\
4.07\end{array}$ & $\begin{array}{c}68.96 \pm \\
3.45\end{array}$ & $\begin{array}{c}92.12 \pm \\
4.61\end{array}$ & $\begin{array}{c}92.89 \pm \\
4.64\end{array}$ & $\begin{array}{c}94.7 \pm \\
4.74\end{array}$ & $\begin{array}{c}88.00 \pm \\
4.40\end{array}$ & $\begin{array}{c}100 \\
\pm 5.00\end{array}$ & $\begin{array}{c}91.59 \pm \\
4.58\end{array}$ & $\begin{array}{c}100 \pm \\
5.00\end{array}$ & \begin{tabular}{|c|}
$90.69 \pm$ \\
4.53
\end{tabular} & $\begin{array}{c}100 \pm \\
5.00\end{array}$ \\
\hline p-chlorobenzoic acid & $\begin{array}{c}51.42 \pm \\
2.57\end{array}$ & $\begin{array}{c}54.57 \pm \\
2.73\end{array}$ & $\begin{array}{c}73.59 \pm \\
3.68\end{array}$ & $\begin{array}{c}88.85 \pm \\
4.44\end{array}$ & $\begin{array}{c}84.53 \pm \\
4.23\end{array}$ & $\begin{array}{c}95.05 \pm \\
4.75\end{array}$ & $\begin{array}{c}74.56 \pm \\
3.73\end{array}$ & $\begin{array}{c}94.88 \pm \\
4.74\end{array}$ & $\begin{array}{c}79.86 \pm \\
3.99\end{array}$ & $\begin{array}{c}93.86 \pm \\
4.69\end{array}$ & $\begin{array}{c}93.86 \pm \\
4.69\end{array}$ & $\begin{array}{c}100 \pm \\
5.00\end{array}$ & \begin{tabular}{|c|}
$88.93 \pm$ \\
4.45
\end{tabular} & $\begin{array}{c}100 \pm \\
5.00\end{array}$ & $\begin{array}{c}94.72 \pm \\
4.74\end{array}$ & $\begin{array}{c}100 \pm \\
5.00\end{array}$ & \begin{tabular}{|c|}
$92.78 \pm$ \\
4.64
\end{tabular} & $\begin{array}{c}100 \pm \\
5.00\end{array}$ \\
\hline eugenol & $\begin{array}{c}78.91 \pm \\
3.95\end{array}$ & $\begin{array}{c}81.77 \pm \\
4.09\end{array}$ & $\begin{array}{c}82.04 \pm \\
4.10\end{array}$ & $\begin{array}{c}98.41 \pm \\
4.99\end{array}$ & $\begin{array}{c}88.1 \pm \\
4.41\end{array}$ & $\begin{array}{c}100 \pm \\
5.00\end{array}$ & $\begin{array}{c}84.99 \pm \\
4.25\end{array}$ & $\begin{array}{c}98.41 \pm \\
4.92\end{array}$ & $\begin{array}{c}84.84 \pm \\
4.24\end{array}$ & $\begin{array}{c}100 \pm \\
5.00\end{array}$ & $\begin{array}{c}100 \pm \\
5.00\end{array}$ & $\begin{array}{c}100 \pm \\
5.00\end{array}$ & $\begin{array}{c}98.83 \pm \\
4.94\end{array}$ & $\begin{array}{c}100 \pm \\
5.00\end{array}$ & $\begin{array}{c}100 \pm \\
5.00\end{array}$ & $\begin{array}{c}100 \pm \\
5.00\end{array}$ & $\begin{array}{c}97.60 \pm \\
4.88\end{array}$ & $\begin{array}{c}100 \pm \\
5.00\end{array}$ \\
\hline t-anethol & $\begin{array}{c}96.32 \pm \\
4.82\end{array}$ & $\begin{array}{c}97.53 \pm \\
4.88\end{array}$ & $\begin{array}{c}100 \pm \\
5.00\end{array}$ & $\begin{array}{c}100 \pm \\
5.00\end{array}$ & \begin{tabular}{|l|}
$100 \pm$ \\
5.00
\end{tabular} & \begin{tabular}{|l|}
$100 \pm$ \\
5.00
\end{tabular} & $\begin{array}{l}100 \pm \\
5.00\end{array}$ & $\begin{array}{c}100 \pm \\
5.00\end{array}$ & $\begin{array}{c}100 \pm \\
5.00\end{array}$ & $\begin{array}{c}100 \pm \\
5.00\end{array}$ & $\begin{array}{c}100 \pm \\
5.00\end{array}$ & $\begin{array}{c}100 \pm \\
5.00\end{array}$ & $\begin{array}{c}100 \pm \\
5.00\end{array}$ & $\begin{array}{c}100 \pm \\
5.00\end{array}$ & $\begin{array}{c}100 \pm \\
5.00\end{array}$ & $\begin{array}{c}100 \pm \\
5.00\end{array}$ & $\begin{array}{c}100 \pm \\
5.00\end{array}$ & $\begin{array}{c}100 \pm \\
5.00\end{array}$ \\
\hline
\end{tabular}

- The extraction rates were calculated as the difference between the concentration of the phenolic solution before extraction to the concentration of the phenolic solution after extraction

- *: 4, 5, 6 and 7 are the polymer modifiers

- **: 8 is the neat PDMS, 9, 10, 11 and 12 are the mixture of $(8+4) ;(8+5) ;(8+6)$ and $(8+7)$ respectively. 
Table 4. Adsorption /desorption cycles with the PDMS phases 11 and 12 after 5 hours of contact with the polluants and washed with $10 \mathrm{~mL}$ of methanol for 40 minutes and then 5 hours of contact with the target polyphenols

\begin{tabular}{|c|c|c|c|c|c|c|c|c|c|c|c|c|c|c|c|c|c|c|c|c|}
\hline \multirow{2}{*}{$\begin{array}{l}\text { CYCLES } \\
\text { PDMS Phases }\end{array}$} & \multicolumn{2}{|c|}{$\mathrm{C} 1$} & \multicolumn{2}{|c|}{ C2 } & \multicolumn{2}{|c|}{$\mathrm{C3}$} & \multicolumn{2}{|c|}{ C4 } & \multicolumn{2}{|c|}{ C5 } & \multicolumn{2}{|c|}{ C6 } & \multicolumn{2}{|c|}{ C7 } & \multicolumn{2}{|c|}{ C8 } & \multicolumn{2}{|c|}{ C9 } & \multicolumn{2}{|c|}{ C10 } \\
\hline & 11 & 12 & 11 & 12 & 11 & 12 & 11 & 12 & 11 & 12 & 11 & 12 & 11 & 12 & 11 & 12 & 11 & 12 & 11 & 12 \\
\hline p-hydroxybenzoïc acid & $51 \pm 3$ & $69 \pm 3$ & $48 \pm 2$ & $67 \pm 3$ & $46 \pm 2$ & $65 \pm 3$ & $44 \pm 2$ & $64 \pm 3$ & $45 \pm 2$ & $65 \pm 3$ & $42 \pm 2$ & $64 \pm 3$ & $36 \pm 2$ & $63 \pm 3$ & $34 \pm 2$ & $60 \pm 3$ & $31 \pm 2$ & $58 \pm 3$ & $25 \pm 1$ & $57 \pm 3$ \\
\hline$t$ - caffeic acid & $96 \pm 5$ & $93 \pm 5$ & $94 \pm 5$ & $91 \pm 5$ & $93 \pm 5$ & $91 \pm 5$ & $90 \pm 5$ & $89 \pm 4$ & $89 \pm 4$ & $89 \pm 4$ & $85 \pm 4$ & $87 \pm 4$ & $74 \pm 4$ & $88 \pm 4$ & $61 \pm 3$ & $85 \pm 4$ & $55 \pm 3$ & $82 \pm 4$ & $42 \pm 2$ & $80 \pm 4$ \\
\hline ferrulic acid & $91 \pm 5$ & $92 \pm 5$ & $90 \pm 5$ & $91 \pm 5$ & $89 \pm 4$ & $90 \pm 5$ & $88 \pm 4$ & $89 \pm 4$ & $86 \pm 4$ & $87 \pm 4$ & $83 \pm 4$ & $88 \pm 4$ & $71 \pm 4$ & $85 \pm 4$ & $59 \pm 3$ & $84 \pm 4$ & $53 \pm 3$ & $81 \pm 4$ & $44 \pm 2$ & $82 \pm 4$ \\
\hline benzoic acid & $78 \pm 4$ & $82 \pm 4$ & $74 \pm 4$ & $80 \pm 4$ & $75 \pm 4$ & $81 \pm 4$ & $72 \pm 4$ & $82 \pm 4$ & $71 \pm 4$ & $80 \pm 4$ & $68 \pm 3$ & $79 \pm 4$ & $64 \pm 3$ & $77 \pm 4$ & $57 \pm 3$ & $74 \pm 4$ & $51 \pm 3$ & $73 \pm 4$ & $45 \pm 2$ & $71 \pm 4$ \\
\hline anisic acid & $86 \pm 4$ & $90 \pm 5$ & $82 \pm 4$ & $90 \pm 5$ & $81 \pm 4$ & $88 \pm 4$ & $79 \pm 4$ & $86 \pm 4$ & $77 \pm 4$ & $85 \pm 4$ & $75 \pm 4$ & $84 \pm 4$ & $67 \pm 3$ & $85 \pm 4$ & $55 \pm 3$ & $83 \pm 4$ & $50 \pm 3$ & $79 \pm 4$ & $45 \pm 2$ & $80 \pm 4$ \\
\hline toluic acid & $100 \pm 5$ & $\begin{array}{ll}100 \pm \\
5\end{array}$ & $\begin{array}{ll}100 \pm \\
5\end{array}$ & $\begin{array}{ll}100 \pm \\
5\end{array}$ & $99 \pm 5$ & $97 \pm 5$ & $95 \pm 5$ & $99 \pm 5$ & $94 \pm 5$ & $96 \pm 5$ & $93 \pm 5$ & $95 \pm 5$ & $89 \pm 4$ & $94 \pm 5$ & $85 \pm 4$ & $91 \pm 5$ & $81 \pm 4$ & $90 \pm 5$ & $79 \pm 4$ & $89 \pm 4$ \\
\hline p-chlorobenzoic acid & $100 \pm 5$ & $\begin{array}{ll}100 \pm \\
5\end{array}$ & $\begin{array}{ll}100 \pm \\
5\end{array}$ & $\begin{array}{ll}100 \pm \\
5\end{array}$ & $98 \pm 5$ & $\begin{array}{l}100 \pm \\
5\end{array}$ & $97 \pm 5$ & $98 \pm 5$ & $95 \pm 5$ & $96 \pm 5$ & $92 \pm 5$ & $94 \pm 5$ & $89 \pm 4$ & $95 \pm 5$ & $83 \pm 4$ & $93 \pm 5$ & $82 \pm 4$ & $92 \pm 5$ & $80 \pm 4$ & $90 \pm 5$ \\
\hline eugenol & $100 \pm 5$ & $\begin{array}{ll}100 \pm \\
5\end{array}$ & $\begin{array}{ll}100 \pm \\
5\end{array}$ & $\begin{array}{ll}100 \pm \\
5\end{array}$ & $\begin{array}{l}100 \pm \\
5\end{array}$ & $\begin{array}{ll}100 \pm \\
5\end{array}$ & $\begin{array}{ll}100 & \pm \\
5 & \\
\end{array}$ & 100 & $100 \pm 5$ & $100 \pm 5$ & $100 \pm 5$ & $\begin{array}{ll}100 \pm \\
5\end{array}$ & $98 \pm 5$ & $\begin{array}{ll}100 \pm \\
5\end{array}$ & $96 \pm 5$ & $\begin{array}{ll}100 & \pm \\
5 & \\
\end{array}$ & $97 \pm 5$ & $\begin{array}{ll}100 & \pm \\
5 & \\
\end{array}$ & $91 \pm 5$ & $99 \pm 5$ \\
\hline t-anethol & $100 \pm 5$ & $\begin{array}{ll}100 \pm \\
5\end{array}$ & $\begin{array}{ll}100 \pm \\
5\end{array}$ & $\begin{array}{ll}100 \pm \\
5\end{array}$ & $\begin{array}{l}100 \pm \\
5\end{array}$ & $\begin{array}{l}100 \pm \\
5\end{array}$ & $\begin{array}{ll}100 & \pm \\
5 & \end{array}$ & $\begin{array}{|ll|}100 & \pm \\
5\end{array}$ & $100 \pm 5$ & $100 \pm 5$ & $100 \pm 5$ & $\begin{array}{l}100 \pm \\
5\end{array}$ & $\begin{array}{ll}100 \pm \\
5\end{array}$ & $\begin{array}{ll}100 & \pm \\
5 & \end{array}$ & $99 \pm 5$ & $\begin{array}{ll}100 & \pm \\
5\end{array}$ & $99 \pm 5$ & $\begin{array}{l}100 \pm \\
5\end{array}$ & $97 \pm 5$ & $\begin{array}{l}100 \pm \\
5\end{array}$ \\
\hline
\end{tabular}

